\title{
IMPLEMENTASI PROBLEM BASED LEARNING DALAM PENINGKATAN AKTIFITAS DAN KOGNITIF SISWA SMK
}

\author{
Bernardus Agus Munadi ${ }^{1}$, Endri Triwiyono ${ }^{2}$ \\ ${ }^{1}$ Pendidikan Teknologi dan Kejuruan Program Pasca Sarjana UNY, ${ }^{2}$ Jurusan Pendidikan Teknik Mesin FT UNY \\ Email: bagusmunadi@gmail.com
}

\begin{abstract}
This study aims to improve students' learning activeness and cognitive-learning outcomes using ProblemBased Learning (PBL) on the 2013 Curriculum. The research was a two-cycle action research, conducted in an oxygen-acetylene welding (OAW) practice of SMK Teknik Fabrikasi Logam. There were four stages in each cycle, namely planning, implementation, observation, and reflection. Data were collected by means of observations using checklists and rating-scale instruments and were analyzed descriptively. The result of PBL implementation show that: (1) students' activeness is improved by 11.20\%; (2) students' cognitive-learning outcomes is improved by $5.32 \%$. The cognitive outcomes improvement can be broken down into memorization (86.97\%), comprehension (77.68\%), application (78.77\%), analysis (79.61\%), evaluation (77.97\%) and synthesis (79.16\%); (3) the percentages of students who passed the minimum mastery criteria on the cognitive aspects is $91.31 \%$; and (4) PBL is in line with the scientific approach of the 2013 Curriculum.
\end{abstract}

Keywords: problem-based learning, activeness, cognitive aspect, learning outcome

\begin{abstract}
ABSTRAK
Penelitian ini bertujuan untuk meningkatkan aktivitas pembelajaran dan kemampuan hasil belajar kognitif siswa SMK Teknik Fabrikasi Logam pada pembelajaran las oksi-asetillin dengan menggunakan metode ProblemBased Learning $(P B L)$ sesuai Kurikulum 2013. Metode penelitian menggunakan penelitian tindakan kelas yang dilaksanakan dalam dua siklus. Setiap siklus terdiri dari empat tahapan: perencanaan, pelaksanaan, pengamatan, dan refleksi. Pengumpulan data menggunakan metode observasi dengan instrumen checklist dan rating scale. Data dianalisis secara deskriptif. Hasil penelitian menunjukkan bahwa: 1) penerapan metode PBL pada pembelajaran Las Oksi Asetilin dapat meningkatkan aktivitas pembelajaran siswa sebesar 11,20\%; 2) peningkatan hasil belajar aspek kognitif setelah menerapkan metode PBL adalah sebesar 5,32\% dengan tingkat capaian kemampuan aspek kognitif sebagai berikut: mengingat 86,87\%; memahami 77,68\%; menerapkan 78,77\%; menganalisa 79,61\%; menilai 77,97\%; dan mencipta 79,16\%; 3) siswa yang mencapai Kriteria Ketuntasan Minimal pada hasil belajar aspek kognitif setelah menerapkan metode PBL sebesar 91,31\%; dan 4) Metode PBL selaras dengan pendekatan saintifik pada Kurikulum 2013.
\end{abstract}

Kata kunci: problem-based learning, aktifitas pembelajaran, aspek kognitif, hasil belajar

\section{PENDAHULUAN}

Pendidikan merupakan dasar pembentukan manusia dalam penguasaan ilmu dan cara hidup yang baik dan benar untuk mewujudkan warga bangsa yang kokoh dan mampu berdikari. Penyelenggaraan proses pendidikan di Sekolah Menengah Kejuruan (SMK) yang belum optimal menjadi isu penting bagi pemerintah untuk terus berbenah agar kualitas penyelenggaraan pendidikan sesuai dengan tujuan. Hal ini terbukti dari tingkat pengangguran terbuka per-Agustus 2017 dimana lulusan SMK yang mengganggur diangka 12,59 juta orang atau $10,40 \%$ dari jumlah total pengangguran terbuka (www.bps.go.id).

Berdasarkan kenyataan yang ada tersebut pemerintah melakukan upaya peningkatan mutu SMK melalui revitalisasi SMK (Inpres No 9 Tahun 2016) dibalut dalam implementasi Kurikulum 2013 yang saat ini masih berjalan. Upaya tersebut tidak hanya menyentuh fisik dan instruksi secaraa eksplisit presiden kepada 12 kementerian, akan tetapi pada proses pembelajaran yang dilaksanakan.

Pembelajaran di SMK bertujuan untuk mempersiapkan siswa memasuki dunia kerja dan 
mampu bersaing dalam pasar kerja saat ini dimana kondisi selalu berubah seiring perubahan global dan teknologi yang ada. Sebagai calon tenaga kerja, siswa dihadapkan pada ketidak pastian dan teknologi yang cepat berubah (Thornburg, 2002). Melihat kondisi tersebut tentu diperlukan pembelajaran yang tidak hanya membekali siswa keahlian dasar melainkan juga mampu beradaptasi terhadap perubahan yang ada. Kenyataan yang ada bahwa jika melihat standar nasional pendidikan dan visi 2025, kualitas pembelajaran yang ada belumlah optimal (https://psmk.kemdikbud.go.id/).

Pembelajaran Kurikulum 2013 yang diarahkan pada pendekatan saintifik belumlah sepenuhnya dilakukan. Guru masih mengalami kesulitan dalam penerapannya sehingga sampai saat ini pembelajaran yang dilakukan belum banyak berubah (Herminarto Sofyan, dkk: 2014). Proses pembelajaran yang diberikan belum menanamkan konsep dan prinsip yang jelas yang mengakibatkan cara menganalisa permasalahan masih rendah sehingga penguasaan materi juga tidak maksimal (Abdullah, 2013). Hasil survey di lapangan yang dilakukan pada mata pelajaran produktif yaitu Las Oxy Accetilin (OAW) menunjukan bahwa materi tentang Las Oxy Accetilin masih dipandang sulit dan kompleks. Evaluasi yang diberikan guru berupa tes belum cukup efektif untuk membantu pemahaman baik segi pengetahuan dan proses kognitif siswa. Selama ini siswa hanya terpaku pada proses praktik tanpa diberikan permasalahan yang terjadi di dunia nyata pada umumnya dan hasil tes semester yang terdahulu masih rendah.

Kemampuan berpikir dan pengetahuan dapat diberikan guru dengan memberikan pengalaman belajar terhadap permasalahan sebenarnya (real word) yang dituangkan ke dalam metode pembelajaran (Rusmono, 2012). Permasalahan sebenarnya tentu lebih kompleks dibanding dengan penyederhanaan dalam pembelajaran yang secara langsung memang serba terbatas. Salah satu metode pembelajaran yang diterapkan dan sejalan dengan pemikiran kurikulum 2013 adalah Problem-Based
Learning (PBL) atau pembelajaran berbasis masalah (Herminarto Sofyan, dkk: 2014).

Model pembelajaran Problem Based Learning merupakan metode pembelajaran dengan menerapkan permasalahan sebagai langkah awal dalam mengumpulkan dan mengintegrasikan pengetahuan baru (Boud \& Felleti: 1991). Problem Based Learning mempersiapkan siswa mengembangkan kemampuan kognitif meliputi menalar, berpikir kritis, membuat keputusan, berpikir kreatif sehingga mampu memecahkan permasalahan yang diberikan (Fogarty, 1992: 2). Permasalahan sebagai dasar proses pembelajaran dalam menyelesaikan masalah dengan tepat dan benar. Berawal dari permasalahan tersebut siswa dipacu untuk belajar konsep dan prosedural atau prinsip dalam mempelajari dan menganalisis masalah. Dari hal tersebut maka terbentuk pengetahuan lama bergeser kepada pengetahuan baru berarti berpikir aktif telah berlangsung dalam siklus pembelajaran las oksi asetilen.

Berdasarkan permasalahan di atas, Problem Based Learning harus diterapkan sebagai salah satu upaya peningkatan pembelajaran di SMK. Peningkatakan yang akan diukur yaitu pada ranah kognitif pembelajaran Las Oxy Accetilin (OAW).

\section{METODE}

Penelitian ini menggunakan metode Penelitian Tindakan Kelas (action research). Pemilihan metode ini agar dapat memperbaiki proses belajar mengajar dan diharapkan dapat pula memperbaiki program serta model pembelajaran yang telah berjalan di SMK sesuai dengan kurikulum 2013. Desain penelitian tindakan kelas menggunakan model Kemmis \& Mc. Taggart. 


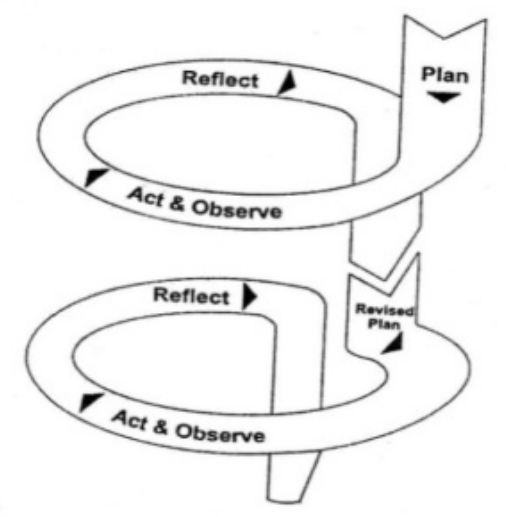

Gambar 1. Desain Penelitian Tindakan Kelas Kemmis \& Taggart (Kemmis \& Taggart: 1988)

Penelitian tindakan kelas terdiri dari empat siklus/tahapan meliputi: proses perencanaan (planing), tindakan (action), observasi (observing), dan refleksi (reflecting) (Pardjono, 2007). Penerapan PBL dilakukan dalam dua siklus. Pengambilan data melalui pretest dan post test serta pengamatan yang dilakukan oleh observer. Lokasi Penelitian dilakukan di SMK N 1 Seyegan Jurusan Fabrikasi Logam.

\section{HASIL DAN PEMBAHASAN}

Data yang diperoleh berupa data aktifitas siswa dan kemampuan hasil belajar yaitu aspek kognitif (pengetahuan) pada materi Las Oxy Accetilin. Penelitian tindakan kelas yang telah dilaksanakan terdiri dari 2 (dua) siklus dengan tahapan yaitu: 1) perencanaan, 2) pelaksanaan, 3) pengamatan, dan 4) refleksi. Aktifitas siswa dalam pembelajaran dinilai berdasarkan keikutsertaan siswa dalam proses pelaksanaan pembelajaran Problem Based Learning yaitu keterlibatan dalam apersepsi, penelusuran data, diskusi, pemecahan masalah dan presentasi.

Hasil penelitian menunjukan aktifitas siswa sebagaimana ditunjukkan pada Tabel 1, mengalami peningkatan pada semua aspeknya dengan rerata peningkatan yaitu sebesar 11,22 \%. Aspek yang paling besar meningkat yaitu pada aspek pemecahan masalah oleh siswa. Sementara peningkatan yang paling rendah pada diskusi siswa.
Tabel 1. Aktifitas Siswa

\begin{tabular}{|c|c|c|c|c|}
\hline No & Aspek & $\begin{array}{c}\text { Siklus } 1 \\
(\%)\end{array}$ & $\begin{array}{c}\text { Siklus 2 } \\
(\%)\end{array}$ & Peningkatan \\
\hline 1 & Apersepsi & 60,3 & 72,4 & 12,1 \\
\hline 2 & Eksplorasi & 55,4 & 67,6 & 12,2 \\
\hline 3 & Diskusi & 64,2 & 68,9 & 4,7 \\
\hline 4 & $\begin{array}{l}\text { Pemecahan } \\
\text { Masalah }\end{array}$ & 43,1 & 65,1 & 22 \\
\hline \multirow[t]{2}{*}{5} & Presentasi & 65,5 & 70,6 & 5,1 \\
\hline & Rerata & 57,7 & 68,92 & 11,22 \\
\hline
\end{tabular}

Berhasil tidaknya pembelajaran dengan menerapkan Problem Based Learning pada siswa dianalisa berdasarkan hasil belajar yang diperoleh siswa. Kemampuan hasil belajar dilakukan di awal pembelajaran dan diakhir setelah penerapan Problem Based Learning. Di awal pembelajaran berupa aspek kognitif pretest untuk mengetahui kemampuan awal sebelum melaksanakan Problem Based Learning sedangkan aspek kognitif post test.

Tabel 2. Peningkatan Hasil Belajar Aspek Kognitif Pretes dan Postes Siswa

\begin{tabular}{clcccc}
\hline \multirow{2}{*}{ No } & $\begin{array}{c}\text { Tingkat } \\
\text { Kemampuan } \\
\text { Kognitif }\end{array}$ & \multicolumn{2}{c}{ Siklus I (\%) } & \multicolumn{2}{c}{ Siklus II (\%) } \\
& Pretest & Postest & Pretest & Postest \\
\hline 1 & Mengingat & 58,97 & 73,21 & 72,69 & 86,87 \\
2 & Memahami & 63,81 & 79,52 & 64,25 & 77,68 \\
3 & Menerapkan & 57,11 & 70,32 & 62,33 & 79,77 \\
4 & Menganalisa & 52,44 & 76,16 & 68,88 & 79,91 \\
5 & Menilai & 58,33 & 72,17 & 70,26 & 79,97 \\
6 & Mencipta & 55,13 & 69,15 & 71,78 & 78,46 \\
& Rerata & 61,72 & 73,83 & 71,04 & 80,44 \\
& KKM & 15 & 80 & 81 & 93,20 \\
\hline
\end{tabular}

Hasil penilaian sebagaimana disajikan pada Tabel 2 menunjukkan peningkatan dari beberapa aspek kemampuan kognitif seperti mengingat, memahami, menerapkan, menganalisis, menilai dan mencipta. Aspek mengingat $86,87 \%$, memahami $77,68 \%$, menerapkan 79,77\%, menganalisis 79,91\%, menilai $78,46 \%$ dan mencipta $78,46 \%$. Rerata kemampuan kognitif yaitu $80,44 \%$ dengan peningkatan siswa yang lulus sesuai Kriteria Ketuntasan Minimum (KKM) 93,20\%.

Peningkatan hasil belajar aspek kognitif siklus II terkait dengan meningkatnya penguasaan pada pelaksanaan pembelajaran dalam Problem Based Learning. Selain itu pada siklus II siswa terlibat aktif dalam pelaksanaan 
Problem Based Learning. Adanya keaktifan tersebut, meningkatkan pengetahuan yang dikuasai siswa. Metode Problem Based Learning dapat meningkatkan kualitas pembelajaran, terbukti dengan keaktifan siswa selama mengikuti proses pembelajaran. Hal ini sejalan dengan apa yang dikemukakan oleh Muhson (2009: 171) bahwa metode Problem Based Learning merupakan metode belajar yang menggunakan masalah sebagai langkah awal dalam proses mengumpulkan dan mengintegrasikan pengetahuan baru, berfokus pada keaktifan peserta didik yang diharapkan dapat mengembangkan pengetahuan mereka sendiri. Sejalan dengan perubahan paradigma dalam proses pembelajaran, yaitu dari yang berorientasi pada guru, menjadi pembelajaran yang berorientasi pada siswa, model Problem Based Learning dapat menjawab permasalahan tersebut.

Beberapa catatan kritis pelaksanaan Problem Based Learning dalam pelaksanaan Kurikulum 2013 yaitu pada dasarnya sekolah dan guru memiliki potensi yang cukup besar dalam mengimplementasikan Problem Based Learning. Guru juga menunjukkan persepsi positif tentang Problem Based Learning dan menyatakan bahwa Problem Based Learning memiliki keunggulan dalam meningkatkan kemampuan siswa dalam aspek aktifitas dan kognitifnya. Sejalan dengan tujuan menerapkan Kurikulum 2013, pengembangan model pembelajaran dengan Problem Based Learning bertujuan untuk meningkatkan kompetensi siswa secara holistik dan integratif dalam aspek pengetahuan, sikap, dan keterampilan. Ada lima tahap utama pembelajaran dengan model Problem Based Learning yaitu orientasi siswa terhadap masalah, mengaatur siswa untuk belajar, membimbing penelitian individu dan kelompok, mengembangkan dan menyajikan hasil kerja, dan menganalisa dan mengevaluasi proses pemecahan masalah.

Terdapat keselarasan antara pendekatan saintifik Kurikulum 2013 dengan Problem Based Learning, sehingga dapat diintegrasikan dalam pelaksanaan Kurikulum 2013
(Herminarto Sofyan, dkk: 2014). Problem Based Learning akan lebih mudah diterapkan apabila didukung dengan materi, media, dan bantuan pengajaran yang lengkap. Dengan materi, media, dan alat bantu pengajaran yang lengkap maka guru akan bebas merancang masalah sesuai dengan karakteristik siswa. Dengan demikian kemampuan guru dalam mengembangkan materi pembelajaran, media, dan bahan ajar merupakan salah satu kunci keberhasilan pelaksanaan PBL.

\section{SIMPULAN}

Metode PBL menjadi salah satu upaya penerapan pendekatan saintifik dalam Kurikulum 2013 yang dinilai masih belum optimal. Penerapan metode PBL pada mata pelajaran Las Oxy Accetilin mampu meningkatkan aktifitas belajar siswa sebesar 11,22\%. Aspek kemampuan kognitif secara rerata meningkat sampai pada $80,44 \%$ dengan rincian mengingat $86,87 \%$, memahami $77,68 \%$, menerapkan 79,77\%, menganalisa 79,91\%, menilai $78,46 \%$ dan mencipta 78,46\%. Sementara Kriteria Ketuntasan Minimum (KKM) meningkat hingga 93,20\%. Hal ini menunjukan bahwa meningkatnya aktifitas siswa berpengaruh pada peningkatan kemampuan kognitif. SMK mempunyai potensi yang cukup besar untuk menerapkan metode PBL sebagai salah satu metode dalam implementasi Kurikulum 2013. Metode PBL dinilai selaras dan sesuai dengan pendekatan saintifik Kurikulum 2013. Penerapan metode PBL akan terbantu dengan adanya materi, media dan alat bantu yang lengkap sebagai penunjang pembelajaran.

\section{DAFTAR RUJUKAN}

Badan Pusat Statistik. (2017). Keadaan Ketenagakerjaan Indonesia Agustus 2017. www.bps.go.id. Diakses pada 11 Desember 2017.

Boud, D., \& Feletti, G. (1997). The challenge of problem-based learning ( $2^{\text {nd }} \quad$ ed.). London: Kogan Page. 
Direkorat Pembinaan SMK. (2017). Target Capaian SMK 2020. http://psmk.kemdikbud.go.id. Diakses ada 12 Desember 2017.

Fogarty. R. (1997). Problem based Learning \& Curriculum Models for the Multiple Intelligences Classroom. Illinois: Sky Light Professional Development.

Herminarto Sofyan, Wagiran, dan Kokom Komariah. (2014). Pengembangan Model pembelajaran Problem based Learning dalam penerapan Kurikulum 2013 di SMK. Laporan Penelitian.

Kemmis \& Taggart. (1988). Action Research and the Critical Analysis of Pedagogy. Geelong: Deakin University.

Lukmanul Hakim Abdulah. (2013). Sistem Penilaian dalam Kurikulum 2013: Kajian Dokumen Terhadap Kurikulum 2013. www.academia.edu. diakses pada 8 Oktober 2017.
Muhson. A. (2009). Peningkatan Minat Belajar dan Pemahaman Mahasiswa Melalui Penerapan Problem Based Learning". Jurnal Kependidikan, 39 (2) , 171-182.

Pardjono, dkk. (2007). Panduan penelitian tindakan kelas. Yogyakarta: LPPM Universitas Negeri Yogyakarta.

Presiden Republik Indonesia. (2016). Instruksi Presiden Republik Indonesia No 9 Tahun 2016 tentang Revitalisasi SMK dalam Rangka Peningkatan Kualitas dan Daya Saing Sumber Daya Manusia Indonesia. Jakarta: Deputi Bidang Pembangunan Manusia dan Kebudayaan.

Rusmono (2012). Strategi Pembelajaran dengan Problem Based Learning. Bogor: Ghalia.

Thornburg, D. (2002). The Basics: Education and the Future of Work in the Telematic Age. Alexandria, VA: Association for Supervision and Curriculum Development. 